\title{
Evaluation of the anti-Listeria potentials of some plant-derived triterpenes
}

\author{
Dambudzo Penduka ${ }^{1 *}$, Rebamang Mosa ${ }^{1}$, Mthokozisi Simelane ${ }^{1}$ Albert Basson ${ }^{1}$, Anthony Okoh² and Andy Opoku
}

\begin{abstract}
Background: Listeriosis is a fatal disease caused by pathogenic Listeria bacteria and it is most prevalent in immune-compromised individuals. The increase in numbers of immune-compromised individuals against a background of Listeria antibiotic resistance, limits listeriosis treatment options. This therefore calls for research into substitute treatments, of which, medicinal plants derived compounds offer a viable alternative.

Methods: The broth microdilution assay was used to determine the minimum inhibitory concentration (MIC) and minimum bactericidal concentration (MBC) of three plant triterpenes namely $3 \beta$-hydroxylanosta-9,24-dien-21-oic

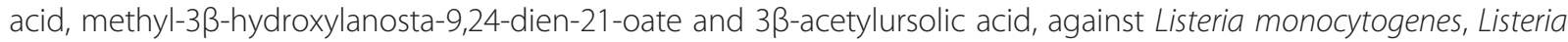
ivanovii and Listeria grayi species. The chequerboard method was used to assess the interactions between the triterpenes and conventional antibiotics: ampicillin, neomycin, gentamicin and penicillin G. The lactate dehydrogenase membrane damage method was used to assess the triterpenes' membrane damaging potentials against the Listeria bacteria.
\end{abstract}

Results: The triterpenes' MIC values were found to range from 0.185 to $1.67 \mathrm{mg} / \mathrm{ml}$ while, the MBC determination assay results revealed that the test triterpenes were bacteriostatic against the Listeria bacteria. The interactions involving 33-hydroxylanosta-9,24-dien-21-oic acid were mainly additive with ampicillin and

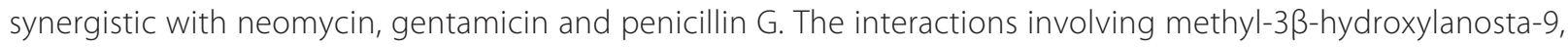
24-dien-21-oate were mainly antagonistic with ampicillin, indifferent with neomycin, ranging from synergistic to indifference with gentamicin and synergistic with penicillin $G$. The interactions involving $3 \beta$-acetylursolic acid were mainly indifferent with ampicillin, synergistic with neomycin and gentamicin while ranging between synergistic and additive with penicillin $\mathrm{G}$. The low levels of cytosolic lactate dehydrogenase released from the cells treated with $4 \times$ MIC concentration of the triterpenes in comparison to that of cells treated with 3\% Triton X-100 proved that membrane damage was not the mode of action of the triterpenes.

Conclusion: This study therefore shows the potential that these plant triterpenes have in listeriosis chemotherapy especially as shown by the favourable interactions they had with penicillin G, one of the antibiotics of choice in listeriosis treatment.

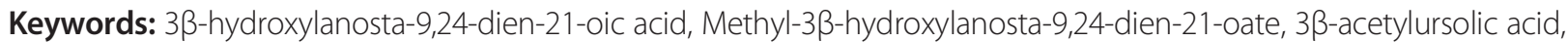
Listeria, Protorhus longifolia, Mimusops caffra

\footnotetext{
* Correspondence: propafadzo@gmail.com

'Department of Biochemistry and Microbiology, University of Zululand, P Bag

X1001, 3886 KwaDlangezwa, South Africa

Full list of author information is available at the end of the article
} 


\section{Introduction}

There are currently fifteen known Listeria species [1], but only two of the species are known to be pathogenic; $L$. monocytogenes is pathogenic to humans and animals while $L$. ivanovii is pathogenic to animals only. L. monocytogenes causes the human fatal disease listeriosis with a case fatality rate of $20-30 \%$; the disease can be in either of two forms, gastrointestinal non-invasive listeriosis which is usually self-limiting or the invasive listeriosis which can be fatal [2].

Contaminated foods such as raw vegetables, meats and ready to eat foods are the major source of pathogenic Listeria, such that the gastrointestinal tract is the bacteria's primary site of entry [3]. The bacteria then colonises the intestine leading to intestinal translocation and at this stage the listeriosis is non-invasive however, if the immune system does not control the infection, the listeriosis progresses to become invasive as the pathogen disseminates to the bloodstream and mesenteric lymph nodes $[2,4]$. The bacterium may then replicate in the liver and spleen, such that control of the bacterium at this point is dependent upon $\mathrm{T}$ cell-mediated immunity. However, in immune-compromised individuals the Listeria spreads to the central nervous system or in the case of pregnant women it crosses the placental barrier resulting in infection of the foetus $[2,4,5]$.

The pathogenic Listeria has an intracellular life cycle that includes invading host cells by using adhesion proteins internalin A and internalin B to bind to the host-cell membrane receptors E-cadherin and Met, replication in the cytoplasm after phagosomal escape and cell to cell spread through ActA surface proteins' polymerization of actin [6,7].

Ampicillin and penicillin $G$ are the first line drugs of choice for listeriosis treatment, with them being used in combination with an aminoglycoside mostly gentamicin in high risk patients (neonates aged less than 1 month, the elderly, immune-compromised individuals, pregnant women). Meropenem may be used in patients with mild allergies to penicillin, while sulfamethoxazole in combination with trimethoprim or vancomycin in combination with teicoplanin can be used in patients with severe allergies $[7,8]$.

The administration of appropriate and effective antibiotic therapy in high-risk patients to prevent invasive listeriosis is imperative [7]. A number of factors have however, limited listeriosis treatment options. The factors include; the characteristic life cycle of pathogenic Listeria to multiply intracellularly and spread from cell-to-cell without leaving the protective environment of the host's cells [4]; the limited treatment options due to the negative side effects of some of the antibiotics especially in pregnant women, children, patients with allergies and in organ transplant recipients [7]; the high mortality rate even despite early antibiotic treatment [8] and the reports on antibiotic resistance among Listeria species [9]. These factors therefore, show the need for a continuous search for newer and more effective listeriosis treatment options.

Medicinal plants have been used since time immemorial to treat various types of illnesses and most have formed the basis of some effective antimicrobial agents [10]. In this connection this study focused on the antiListerial activities of three triterpenes isolated from two traditional medicinal plants namely Protorhus longifolia and Mimusops caffra. Plant triterpenes comprise a diverse chemical group of active principles and have been reported to possess anti-inflammatory, antiviral, antimicrobial, and antitumor activities [11].

Protorhus longifolia is an evergreen plant that grows up to a height of $18 \mathrm{~m}$ with a trunk diameter of about $1 \mathrm{~m}$ and belongs to the tropical and sub-tropical family of Anacardiaceae [12]. The genus Protorhus Engl is mostly found in Madagascar and only two species are found in Africa namely Protorhus namaquensis (Namibian/South African border) and Protorhus longifolia found in southern parts of Africa, and mostly abundant in the sub-tropical forests of KwaZulu Natal in South Africa [12]. The tea from the mixture of the barks of Protorhus longifolia and Hippobromus pauciflorus is known to treat heartwater and diarrhea in cows [13]. Its leaf extracts have been shown to possess both antibacterial and antifungal activities in-vitro [14] and Mosa et al. [15] isolated two triterpenes from the chloroform extract of the bark namely 3-oxo-5 $\alpha$-lanosta-8,24-dien-21-oic acid and $3 \beta$ hydroxylanosta-9,24-dien-21-oic acid, which exhibited anti-platelet aggregation activities.

Mimusops caffra belongs to the Sapotaceae family and the genus Mimusops consists of 30 species, some of which grow in tropical and sub-tropical regions of Asia [16]. Mimusops caffra can be found in Southern Africa especially in Mozambique and in the Kwazulu Natal and Eastern Cape provinces of South Africa [17]. Its traditional medicinal properties include wounds and sore healing [17]. Ursolic acid isolated from the leaves of the plant, was shown to exhibit anti-plasmodial activities against Plasmodium falciparum (D10) [17].

Herein, this study provides a scientific basis for the antiListeria activities of 33-hydroxylanosta-9,24-dien-21-oic acid and methyl-3 $\beta$-hydroxylanosta-9,24-dien-21-oate isolated from Protorhus longifolia and $3 \beta$-acetylursolic acid a derivative of ursolic acid which was isolated from Мimusops caffra in-vitro.

\section{Method}

\section{Test triterpenes}

The 3ß-hydroxylanosta-9,24-dien-21-oic acid and methyl$3 \beta$-hydroxylanosta-9,24-dien-21-oate were previously isolated and characterized from the stem bark of Protorhus 
longifolia by Mosa et al. [15] and Mosa [18] respectively. The $3 \beta$-acetylursolic acid was previously derivatised from ursolic acid isolated from the leaves of Mimusops caffra by Simelane et al. [17]. The chemical structures of the triterpenes are as shown in Figures 1, 2 and 3.

\section{Test antibiotics}

The antibiotics penicillin G, ampicillin, neomycin and gentamicin obtained from Sigma (South Africa) were used. These were dissolved in sterile distilled water to make the test concentration.

\section{Test Listeria}

The test Listeria was obtained from the culture collection of the Applied and Environmental Microbiology Research Group (AEMREG) at the University of Fort Hare, Alice, South Africa. The organisms included a referenced Listeria monocytogenes ATCC- 19115 strain as well as environmental isolates of Listeria grayi (LAL 3) and Listeria ivanovii (LDB 11) both previously isolated from waste water effluents by Odjadjare et al. [19].

\section{MIC determination}

The MIC's of the triterpenes were determined according to the microbroth dilution method of EUCAST [20] as described by Penduka and Okoh [21] in 96 well microtiter plates. The test Listeria was standardised to match the 0.5 McFarland standard. A starting concentration of $5 \mathrm{mg} / \mathrm{ml}$ of each triterpene dissolved in 10\% DMSO was serially diluted double fold in double strength Mueller-Hinton Broth to make different test concentrations of the compounds in the wells. A volume of $20 \mu \mathrm{l}$ of the test organisms was introduced to $100 \mu \mathrm{l}$ of the test triterpene in broth. The antibiotics penicillin G, ampicillin, neomycin and gentamicin were used as positive controls. The 10\% DMSO was also tested for its possible anti-Listeria activities. Sterility wells were also included and the whole assay was perfomed in triplicates. The plates were then incubated at $37^{\circ} \mathrm{C}$ for $18-24 \mathrm{~h}$, after which results were

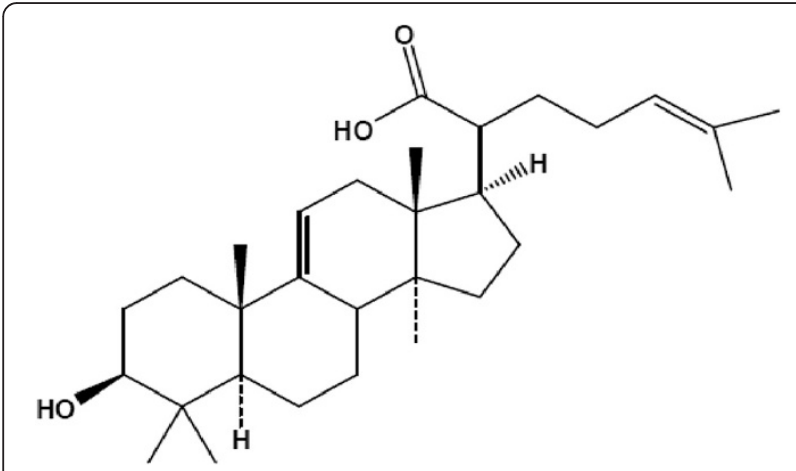

Figure 1 Chemical structure of 3 3 -Hydroxylanosta-9, 24-dien-21-oic acid [15].

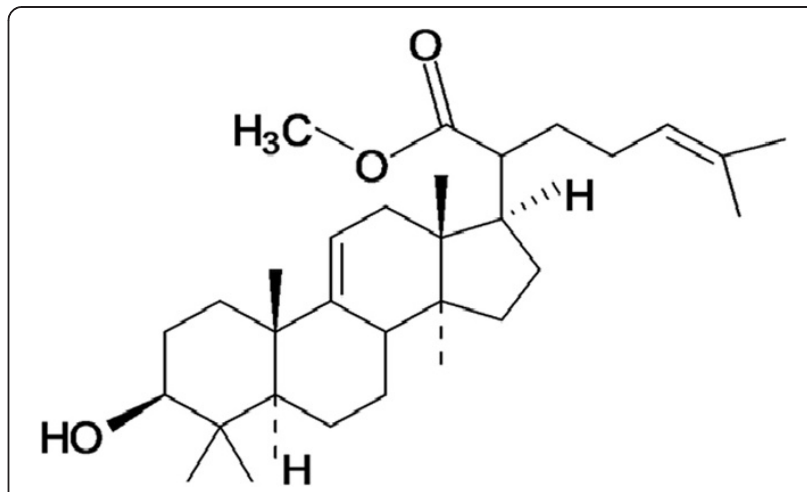

Figure 2 Chemical structure of methyl-3 $\beta$-hydroxylanosta-9, 24-dien-21-oate [18].

read visually by adding $40 \mu \mathrm{l}$ of $0.2 \mathrm{mg} / \mathrm{ml}$ of $\rho$ iodonitrotetrazolium violet (INT) into each well. A colour change (viewing with the naked eye) from colourless to purple, indicated actively growing bacteria based on the oxidation-reduction reaction in which electrons are transferred from NADH (a product of the oxidation of threonine to 2-amino-3-ketobutyrate) to INT which then forms the red formazan which is purple in colour. The MIC was recorded as the lowest concentration of the triterpene or antibiotic that prevented the growth of the organism after 18-24 h.

\section{$M B C$ determination}

The MBC was determined using the method described by Sudjana et al. [22] with some minor modifications. Briefly, the test triterpenes and antibiotics were serially diluted in double strength Mueller-Hinton broth in 96 well microtitre plates to make different test concentrations starting with $8 \times$ MIC value of the test antibacterial agent up to its MIC value against each organism. The test Listeria was standardised to match the 0.5 McFarland standard and $20 \mu \mathrm{l}$ of the organism was inoculated into each well containing $100 \mu \mathrm{l}$ of the test antibacterial agent in broth.

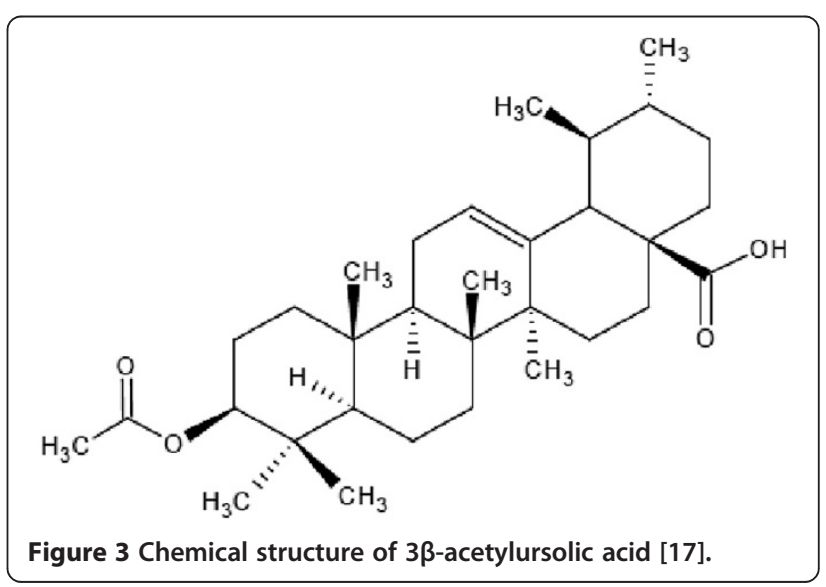


The plates were incubated for 18-24 h after which $15 \mu \mathrm{l}$ was subcultured from each well and inoculated onto fresh Mueller-Hinton agar plates. The agar plates were then incubated for 18-24 h after which the MBC was interpreted as the minimum concentration of the antibacterial agent that prevented the growth of viable colonies on the Mueller-Hinton agar after incubation.

\section{Interactions}

The interactions between the triterpenes and selected antibiotics were perfomed in 96 well microtiter plates as described by Penduka et al. [23] using the chequerboard method. The starting antimicrobial combination in double strength Mueller-Hinton broth was serially diluted to make different test concentrations in the microtiter plate, with each well containing $100 \mu \mathrm{l}$ of the test antimicrobial combination. A volume of $20 \mu \mathrm{l}$ of the standardised 0.5 MacFarland test bacteria was added into the test wells. Sterility wells containing the broth only and growth control wells containing the bacteria and broth only were also added in each microtitre plate. The MIC's of the test combination were determined after $18-24 \mathrm{~h}$ of incubation at $37^{\circ} \mathrm{C}$ using the same INT method mentioned in the MIC determination. The interactions were interpreted through the use of Fractional Inhibitory Indices (FIC). The FIC index of a triterpene $\left(\mathrm{FIC}_{\mathrm{T}}\right)$ was calculated as the ratio of the MIC value of the triterpene in combination over the MIC value of the triterpene alone, and the FIC index of the antibiotic $\left(\mathrm{FIC}_{\mathrm{A}}\right)$ was calculated as the ratio of the MIC value of the antibiotic in combination over the MIC value of the antibiotic alone. The overall FIC index ( $\mathrm{FIC}$ ) was calculated as the summation of the $\mathrm{FIC}_{\mathrm{T}}$ and the $\mathrm{FIC}_{\mathrm{A}}$. The interactions were interpreted as synergism when the $\Sigma F I C$ index $\leq 0.5$, additive when $0.5<\Sigma F I C$ index $\leq 1$, and indifference when $1<\Sigma F I C$ index $<4$ whilst antagonism was defined as when the $\Sigma$ FIC index is $\geq 4$. The test was perfomed in triplicates.

\section{Cytosolic lactate dehydrogenase assay for membrane damage determination}

The cytosolic lactate dehydrogenase assay was carried out according to the methodology described by Soyingbe et al. [24] with some modifications. Standardized test Listeria cultures matching 0.5 MacFarland standard were grown for $18-24 \mathrm{~h}$ in a concentration of $4 \times \mathrm{MIC}$ value of each triterpene after which, the mixture was centrifuged $(5000 \times \mathrm{g}$ for $5 \mathrm{mins})$. An aliquot of $50 \mu \mathrm{l}$ from the supernatant was incubated with $50 \mu \mathrm{l}$ mixed reaction solutions of a lactate dehydrogenase (LDH) activity assay kit (Sigma Aldrich), at room temperature and incubated for $30 \mathrm{~min}$. After which, the absorbance was measured at $492 \mathrm{~nm}$ using a 96 well microplate reader (BiotekELx 808). Cultures grown in $3 \%$ Triton $\mathrm{X}-100$ were used as the positive control. The extent of membrane damage was calculated as $(\mathrm{E}-\mathrm{C}) /(\mathrm{T}-\mathrm{C}) \times 100$, where $\mathrm{E}$ is the experimental absorbance of the cell cultures incubated with the test triterpenes, $\mathrm{C}$ is the control absorbance of the cell medium and $\mathrm{T}$ is the $3 \%$ Triton $\mathrm{X}-100$ treated cells supernatant.

\section{Statistical analysis}

The results were reported as mean values of triplicate experiments.

\section{Results}

\section{MIC determination}

The MIC values of the triterpenes and the antibiotics are as shown in Table 1. The triterpenes isolated from P. longifolia had an MIC value of $0.185 \mathrm{mg} / \mathrm{ml}$ against all the three test Listeria bacteria, while the $3 \beta$-acetylursolic acid had an MIC value of $1.67 \mathrm{mg} / \mathrm{ml}$ against all the three Listeria bacteria. The 10\% DMSO was found not to exhibit anti-Listeria activities in-vitro.

\section{MBC determination}

The results of the $\mathrm{MBC}$ determination are as shown in Table 2. All the triterpenes were bacteriostatic against the Listeria at a maximum concentration of $8 \times$ MIC value of

Table 1 MIC determination of the triterpenes against the test Listeria bacteria

\begin{tabular}{|c|c|c|c|}
\hline Test antibacterial agent & L. monocytogenes & L. ivanovii & L. grayi \\
\hline 3ß-hydroxylanosta-9,24-dien-21-oic acid (mg/ml) & 0.185 & 0.185 & 0.185 \\
\hline methyl-3ß-hydroxylanosta-9,24-dienoate (mg/ml) & 0.185 & 0.185 & 0.185 \\
\hline 3ß-acetylursolic acid (mg/ml) & 1.67 & 1.67 & 1.67 \\
\hline ampicillin $(\mu \mathrm{g} / \mathrm{ml})$ & 0.014 & 0.005 & $\mathrm{R}$ \\
\hline penicillin G ( $\mu \mathrm{g} / \mathrm{ml})$ & 0.079 & 0.079 & $\mathrm{R}$ \\
\hline neomycin $(\mu \mathrm{g} / \mathrm{ml})$ & 0.019 & 0.157 & 1.25 \\
\hline gentamicin $(\mu \mathrm{g} / \mathrm{ml})$ & 0.157 & 0.157 & 0.625 \\
\hline $10 \%$ DMSO & NA & NA & NA \\
\hline
\end{tabular}

Note: $\mathrm{R}$ denotes resistance towards the test antibacterial agent at a maximum test concentration of $100 \mu \mathrm{g} / \mathrm{ml}$ and NA denotes not active. 
Table 2 MBC determination of the triterpenes against the test Listeria bacteria

\begin{tabular}{|c|c|c|c|}
\hline Test antibacterial agent & L. monocytogenes & L.ivanovii & L.grayi \\
\hline 3ß-hydroxylanosta-9,24-dien-21-oic acid (mg/ml) & $>1.48$ & $>1.48$ & $>1.48$ \\
\hline methyl-3ß-hydroxylanosta-9,24-dienoate (mg/ml) & $>1.48$ & $>1.48$ & $>1.48$ \\
\hline 3ß-acetylursolic acid (mg/ml) & $>13.36$ & $>13.36$ & $>13.36$ \\
\hline ampicillin $(\mu \mathrm{g} / \mathrm{ml})$ & $>0.112$ & $>0.04$ & $\mathrm{R}$ \\
\hline penicillin G ( $\mu \mathrm{g} / \mathrm{ml})$ & $>0.632$ & $>0.632$ & $\mathrm{R}$ \\
\hline neomycin $(\mu \mathrm{g} / \mathrm{ml})$ & $>0.152$ & $>1.26$ & 10 \\
\hline gentamicin $(\mu \mathrm{g} / \mathrm{ml})$ & $>1.26$ & $>1.26$ & 5 \\
\hline
\end{tabular}

Note: $\mathrm{R}$ denotes resistance towards the test antibacterial agent at a maximum test concentration of $100 \mu \mathrm{g} / \mathrm{ml}$.

the test triterpene. The antibiotics were also mostly bacteriostatic except for neomycin and gentamicin against L. grayi whereby the antibiotics were bactericidal.

Interactions of the triterpenes and conventional antibiotics The interactions of the triterpenes and conventional antibiotics are as shown in Tables 3, 4, and 5. Penicillin $\mathrm{G}$ had synergistic and additive interactions only, while neomycin and gentamicin had interactions ranging from synergistic to indifference and ampicillin had interactions ranging from additive to antagonistic with the test triterpenes.

\section{Membrane damage activity of the triterpenes}

The triterpenes showed low levels of cytosolic lactate dehydrogenase release as shown in Table 6. The overall highest cytosolic lactate dehydrogenase released was $18.8 \%$ against $L$. monocytogenes by $3 \beta$-hydroxylanosta9,24-dien-21-oic acid and the lowest being $0.02 \%$ against L. ivanovii by $3 \beta$-hydroxylanosta-9,24-dien-21-oic acid .

\section{Discussion}

Triterpenes especially those isolated from medicinal plants have a high potential of use as pharmacological agents [11]. Plant compounds are usually classified as being antimicrobial based on MIC ranges of 100 to $1000 \mu \mathrm{g} / \mathrm{ml}$ while, those of typical antibiotics produced by bacteria or fungi are acceptable antimicrobials at much lower ranges of MICs between 0.01 and $10 \mu \mathrm{g} / \mathrm{ml}$ [25]. The triterpenes used in this study showed appreciable antibacterial activities against the three Listeria species although the $3 \beta$ acetylursolic acid had MICs outside the range acceptable

Table 3 Interactions of $3 \beta$-hydroxylanosta-9, 24-dien-21-oic acid and the different antibiotics

\begin{tabular}{llll}
\hline & L. grayi & L. monocytogenes & L. ivanovii \\
\hline Ampicillin & ND & (1) Additive & (1) Additive \\
Penicillin G & ND & (0.498) Synergy & (0.498) Synergy \\
Neomycin & (0.375) Synergy & (0.75) Additive & (0.497) Synergy \\
Gentamicin & (0.245) Synergy & (0.314) Synergy & $(1.25)$ Indifference \\
\hline
\end{tabular}

Note: ND denotes not determined and (number) denotes the $\Sigma$ FIC index value. for plant compounds. The triterpenes even had activities against L. grayi which was resistant towards the first line antibiotics of choice ampicillin and penicillin G. L. grayi is not normally a pathogenic species however, Salimnia et al. [26] reported a case of L. grayi bacteremia in a stem cell transplant recipient, showing the potential pathogenicity of this species as well, such that reports of its resistance to the penicillins are worrisome.

Combined therapy in listeriosis treatment is a wellaccepted concept as shown by the different treatment options against listeriosis mentioned previously $[7,8]$. In this connection, interactions between the triterpenes and the antibiotics in the penicillins (penicillin G and ampicillin) and aminoglycosides (gentamicin and neomycin) groups were tested in this study. Generally penicillin $G$ had the most favourable interactions with the triterpenes in comparison to all the other antibiotics as it had more synergistic interactions with the triterpenes, while ampicillin had the least favourable interactions. The contrasting results observed between how the penicillins interacted with the same triterpenes against the same organism can be attributed to the differences in their chemical structures. Penicillins consist of a thiazolidine ring connected to a beta-lactam ring attached to a side chain. Ampicillin has an amino group on the benzyl side chain and this differentiates it from penicillin $G$ of which the side chain determines most pharmacologic characteristics of each penicillin [27].

Generally $3 \beta$-hydroxylanosta-9,24-dien-21-oic acid was the triterpene that exhibited mainly synergistic and additive interactions with all the antibiotics against all the test Listeria. New findings of anti-Listeria agents that

Table 4 Interactions of methyl-3 $\beta$-hydroxylanosta-9, 24-dien-21-oate and the different antibiotics

\begin{tabular}{llll}
\hline & L. grayi & L. monocytogenes & L. ivanovii \\
\hline Ampicillin & ND & (4) Antagonistic & (4) Antagonistic \\
Penicillin G & ND & (0.498) Synergy & (0.498) Synergy \\
Neomycin & (1.5) Indifference & (3.05) Indifference & (1.01) Indifference \\
Gentamicin & (1) Additive & (0.314) Synergy & (1.25) Indifference
\end{tabular}

Note: ND denotes not determined and (number) denotes the $\Sigma$ FIC index value. 
Table 5 Interactions of $3 \beta$-acetylursolic acid and the different antibiotics

\begin{tabular}{llll}
\hline & L. grayi & L. monocytogenes & L. ivanovii \\
\hline Ampicillin & ND & (1.11) Indifference & $(1.11)$ Indifference \\
Penicillin G & ND & (1) Additive & (0.498) Synergy \\
Neomycin & (0.264) Synergy & $(1.06)$ Indifference & $(0.276)$ Synergy \\
Gentamicin & (0.25) Synergy & (0.156) Synergy & $(1.25)$ Indifference \\
\hline
\end{tabular}

Note: ND denotes not determined and (number) denotes the $\Sigma F I C$ index value.

are non-toxic and possess synergistic interactions with conventional antibiotics against Listeria bacteria are significant as the current combinations involving gentamicin have nephrotoxicity risks $[28,29]$, while those involving sulfamethoxazole-trimethoprim have potential risks of causing kernicterus to the foetus and folic acid metabolism disturbances in pregnant women [7]. The triterpenes used in this study have however, been found to be nontoxic (with $\mathrm{IC}_{50}$ values that were higher than $300 \mu \mathrm{g} / \mathrm{ml}$ ) against some tested human cell lines $[15,17,18]$. Compounds are considered significantly toxic when they have an $\mathrm{IC}_{50}$ value of less than $30 \mu \mathrm{g} / \mathrm{ml}[17,30]$.

The MBC determination assay showed all the triterpenes to be generally bacteriostatic against the Listeria bacteria, however, in a bid to understand more on how the triterpenes effect their anti-Listeria activities invitro, the cytosolic lactate dehydrogenase test was carried out to determine if membrane damage is their mode of action. The results however, indicated that membrane damage is not the main mode of action of the triterpenes. This was evidenced by the low percentage of cytosolic lactate dehydrogenase released from the cells treated with the triterpenes (Table 6). Essential oils on the other hand which are typically a mixture of terpenes and/or terpenoids are postulated to exhibit antibacterial activity by disrupting the permeability barrier of microbial membrane structures [31], with some studies even showing the membrane disrupting activities of some plants essential oils against both Gram negative and Gram positive bacteria [24,31].

The findings of this study however, have shown membrane damage by the triterpenes to be very minimal, such that it can be hypothesised that the triterpenes act on multiple target sites and their major mode of action

\begin{tabular}{|c|c|c|c|}
\hline Test Triterpene & L. grayi & L. monocytogenes & L. ivanovii \\
\hline $\begin{array}{l}\text { 3ß-hydroxylanosta-9,24- } \\
\text { dien-21-oic acid }\end{array}$ & 0.758 & 18.8 & 0.020 \\
\hline 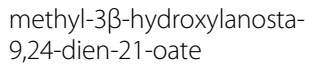 & 0.808 & 1.42 & 0.668 \\
\hline 3ß-acetylursolic acid & 0.334 & 0.090 & 2 \\
\hline
\end{tabular}

may include inhibition of macromolecular synthesis such as DNA or RNA synthesis. The mechanism of action of some triterpenoids against Gram positive bacteria have also been shown to be a combination of plasma membrane disruption and inhibition of macromolecular synthesis such as RNA synthesis [32]. A study by Cristani et al. [33] also showed that the antimicrobial activities of some terpenes to be probably a resultant of partial agitation of the lipidic fraction of the plasma membrane in addition to the terpenes interacting with intracellular sites which are critical for bacterial growth [33].

The resultant synergistic results observed in this study can hypothetically be a combination of the protein synthesis inhibition properties of the aminoglycosides [34] or the cell wall inhibition properties of the penicillins (especially penicillin G in this study) [35] and the macromolecular synthesis inhibition properties of the triterpenes. In addition to the findings of this study, some previous studies have shown the methyl-3 $\beta$-hydroxylanosta-9,24-dien-21-oate and $3 \beta$-hydroxylanosta-9,24-dien-21-oic acid to possess anti-inflammatory, anti-hyperlipidemic, anti-coagulant activities $[15,18]$, while the $3 \beta$-acetylursolic acid has been shown to possess anti-plasmodial activities [17].The various bioactivities of the triterpenes together show their multiple beneficial health effects potentials, such that their use in listeriosis treatment especially in the immunecompromised is highly likely to be advantageous.

\section{Conclusion}

The three triterpenes tested possessed varying levels of anti-Listeria activities and also some synergistic interactions with conventional listeriosis treatment antibiotics invitro showing their potential in alternative listeriosis treatment. A follow up of the study with in-vivo tests would be highly recommended to ascertain if the observed in-vitro results align with the in-vivo results and also to determine if the synergistic interactions observed also result in bactericidal action.

\section{Competing interests}

The authors declare that they have no competing interests.

\section{Authors' contributions}

DP wrote the manuscript and carried out the experimental studies. RM and MS supplied the triterpenes. All the authors participated in the design of the study and the critical revision of the manuscript and data content. All

authors read and approved the final manuscript.

\section{Acknowledgements}

The authors would like to acknowledge the Medical Research Council of South Africa and the Research Committee of the University of Zululand for the funding.

\footnotetext{
Author details

'Department of Biochemistry and Microbiology, University of Zululand, P Bag X1001, 3886 KwaDlangezwa, South Africa. ${ }^{2}$ Department of Biochemistry and Microbiology, University of Fort Hare, P. Bag X1314, Alice 5700, South Africa.
} 
Received: 29 April 2014 Accepted: 15 July 2014

Published: 23 July 2014

\section{References}

1. den Bakker HC, Warchocki S, Wright EM, Allred AF, Ahlstrom C, Manuel CS, Stasiewicz MJ, Burrell A, Roof S, Strawn L, Fortes ED, Nightingale KK, Kephart D, Wiedmann M: Five new species of Listeria (L. floridensis sp. nov, L. aquatica sp. nov., L. cornellensis sp. nov. L. riparia sp. nov., and L. grandensis sp. nov.) from agricultural and natural environments in the United States. Int J Syst Evol Microbio/ 2014, doi:10.1099/ijs.0.052720-0 ijs.0.052720-0.

2. Camejo A, Carvalho F, Reis O, Leitao E, Sousa S, Cabanes D: The arsenal of virulence factors deployed by Listeria monocytogenes to promote its cell infection cycle. Virulence 2011, 2(5):379-394.

3. Vazquez-Boland JA, Kuhn M, Berche P, Chakraborty T, Dominguez- Bernal G, Goebel W, Gonzalez-Zorn B, Wehland J, Kreft J: Listeria pathogenesis and molecular virulence determinants. Clin Microbiol Rev 2001, 14:584-640.

4. Orndorff PE, Hamrick TS, Smoak IW, Havell EA: Host and bacterial factors in listeriosis pathogenesis. Vet Microbiol 2006, 114:1-15.

5. Warriner K, Namvar A: What is the hysteria with Listeria? Trends Food Sci Tech 2009, 20:245-254.

6. Guillet $\mathrm{C}$, Join-Lambert $\mathrm{O}$, Monnier AL, Leclercq A, Mechai F, MamzerBruneel M, Bielecka MK, Scortti M, Disson O, Berche P, Vazquez-Boland J, Lortholary O, Lecuit M: Human listeriosis caused by Listeria ivanovii. Emerg Infect Dis 2010, 16(1):136-138.

7. Mardis BA, Conley CS, Kyle JA: Listeriosis: An overview. US Pharm 2012, 37(8):38-41.

8. Swaminathan B, Gerner-Smidt P: The epidemiology of human listeriosis. Microb Infect 2007, 9:1236-1243.

9. Soni DK, Singh RK, Singh DV, Dubey SK: Characterization of Listeria monocytogenes isolated from Ganges water, human clinical and milk samples at Varanasi, India. Infect Gen Evol 2013, 14:83-91.

10. Cowan MM: Plants products as antimicrobial agents. Clin Microbiol Rev 1999, 12(4):564-582

11. Rios J-L: Effects of triterpenes on the immune system. J Ethnopharmacol 2010, 128:1-14.

12. von Teichman I: Pericarp structure in Protorhus longifolia (Bernh.) Engl. (Anacardiaceae) and its taxonomic significance. Bot Bull Academia Sinica 1991, 32:121-128.

13. Dold AP, Cocks ML: Traditional veterinary medicine in the Alice district of the Eastern Cape Province, South Africa. SA J Sci 2001, 97:375-379.

14. Suleiman MM, McGaw $L$, Naidoo V: Evaluation of several tree species for activity against the animal fungal pathogen Aspergillus fumigatus. SA J Bot 2009. doi:10.1016/j.sajb.2009.07.001.

15. Mosa RA, Oyedeji AO, Shode FO, Singh M, Opoku AR: Triterpenes from the stem bark of Protorhus longifolia exhibit anti-platelet aggregation activity. Afr J Pharm Pharmacol 2011, 5(24):2698-2714.

16. Shahwar D, Raza MA: In vitro antibacterial activity of extracts of Mimusops elengi against Gram positive and Gram negative bacteria. Afr J Microbiol Res 2009, 3(8):458-462

17. Simelane MBC, Shonhai A, Shode FO, Smith P, Singh M, Opoku AR: Anti-Plasmodial Activity of some Zulu medicinal plants and of some triterpenes isolated from them. Molecules 2013, 18:12313-12323.

18. Mosa RA: Some bioactivity of triterpenes from stem bark of Protorhus longifolia and their derivatives. In PhD thesis. KwaDlangezwa, South Africa: University of Zululand, Department of Biochemistry and Microbiology; 2014.

19. Odjadjare EEO, Obi LC, Okoh Al: Municipal wastewater effluents as a source of Listerial pathogens in the aquatic milieu of the Eastern Cape Province of South Africa: A concern of public health importance. Int J Environ Res Public Health 2010, 7:2376-2394.

20. EUCAST (European Committee for Antimicrobial Susceptibility Testing) Determination of minimum inhibitory concentration (MICs) of antimicrobial agents by broth dilution. Clin Microbiol Infect 2003, 9:1-7.

21. Penduka D, Okoh Al: Antibacterial potentials of the crude dichloromethane extract of Garcinia kola (Heckle) seeds against some Listeria species isolated from wastewater effluents. J Pure Appl Microbiol 2013, 7(2):1055-1063.

22. Sudjana AN, D'Orazio C, Ryan V, Rasool N, Ng J, Islam N, Riley TV, Hammer KA: Antimicrobial activity of commercial Olea europaea (olive) leaf extract. Int J Antimicrob Agents 2009, 33:461-463.

23. Penduka D, Buwa L, Mayekiso B, Basson AK, Okoh Al: Identification of the antiListerial constituents in partially purified column chromatography fractions of Garcinia kola seeds and their interactions with standard antibiotics. Evidence-Based CAM 2014, doi:10.1155/2014/850347.

24. Soyingbe OS, Oyedeji A, Basson AK, Opoku AR: The essential oil of Eucalyptus grandis W. Hill ex Maiden inhibits microbial growth by inducing membrane damage. Chin Med 2013, 4:7-14.

25. Tegos G, Stermitz FR, Lomovskaya O, Lewis K: Multidrug pump inhibitors uncover remarkable activity of plant antimicrobials. Antimicrob Agents Chemother 2002, 46(10):3133-3141.

26. Salimnia H, Patel D, Lephart PR, Fairfax MR, Chandrasekar PH: Listeria grayi: vancomycin-resistant, gram-positive rod causing bacteremia in a stemcell transplant recipient. Transp Infect Dis 2010, 12:526-528.

27. Glover DD, Lalka D, Monif GRG: Ampicillin vs. Penicillin for in utero therapy. Infect Dis Obstet Gynecol 1996, 4:43-46.

28. Mitja O, Pigrau C, Ruiz I, Vidal X, Almirante B, Planes AM, Molina I, Rodriguez D, Pahissa A: Predictors of mortality and impact of aminoglycosides on outcome in listeriosis in a retrospective cohort study. J Antimicrob Chemother 2009, 64:416-423.

29. Amaya-Villar R, García-Cabrera E, Sulleiro-Igual E, Fernández-Viladrich P, Fontanals-Aymerich D, Catalán-Alonso P, Rodrigo-Gonzalo de Liria C, Coloma-Conde A, Grill-Díaz F, Guerrero-Espejo A, Pachon J, Prats-Pastor G: Three-year multicenter surveillance of community-acquired Listeria monocytogenes meningitis in adults. BMC Infect Dis 2010, 10:324.

30. Suffness M, Pezzuto JM: Assays related to cancer drug discovery. In Methods in plant biochemistry: Assays for Bioactivity. Edited by Hostettman K. London UK: Academic Press; 1990:71-133.

31. Cox SD, Mann CM, Markham JL, Bell HC, Gustafson JE, Warmington JR, Wyllie SG: The mode of antimicrobial action of the essential oil of Melaleuca alternifolia (tea tree oil). J Appl Microbiol 2000, 88:170-175.

32. de Leon L, Moujir L: Activity and mechanism of the action of zeylasterone against Bacillus subtilis. J Appl Microbiol 2008, 104:1266-1274.

33. Cristani M, D'Arrigo M, Mandalari G, Castelli F, Sarpietro MG, Micieli D, Venuti V, Bisignano G, Saija A, Trombetta D: Interaction of four monoterpenes contained in essential oils with model membranes: Implications for their antibacterial activity. J Agric Food Chem 2007, 55(15):6300-6308.

34. Levy SB, Marshall B: Antibacterial resistance worldwide causes, challenges and response. Nat Med 2004, 10(12):S122-S129.

35. Jury KL, Vancov T, Stuetz RM, Khan SJ: Antibiotic resistance dissemination and sewage treatment plants. In Current research, technology and education topics in applied microbiology and microbial biotechnology. Edited by Mendez-Vilas A; 2010:509-519.

doi:10.1186/s12941-014-0037-

Cite this article as: Penduka et al:: Evaluation of the anti-Listeria potentials of some plant-derived triterpenes. Annals of Clinical Microbiology and Antimicrobials 2014 13:37.

\section{Submit your next manuscript to BioMed Central and take full advantage of:}

- Convenient online submission

- Thorough peer review

- No space constraints or color figure charges

- Immediate publication on acceptance

- Inclusion in PubMed, CAS, Scopus and Google Scholar

- Research which is freely available for redistribution 